\title{
OBITUARI: JUAN VALERO (1937-2019)
}

\author{
XAVIER ESPLUGA \\ Universitat de Barcelona \\ xespluga@ub.edu \\ ORCID: 0000-0002-6690-1974
}

El proppassat 5 de juliol de 2019 va morir, a Sitges, Juan Valero Garrido (1937-2019) que durant molts anys havia estat professor titular de Filologia Grega de la Universitat de Barcelona. Valero havia nascut a Salvacañete, localitat de la província espanyola de Conca; en els anys més miserables de la postguerra que s'allargava sense fi, inicià els estudis al seminari d'Uclés i a la capital provincial, en concret, a l'Instituto Nacional de Enseñanza Media Alfonso VIII'; hi restà fins acabar el batxillerat l'any 1959 i aleshores es traslladà a Barcelona per apuntar-se a la Facultat de Filosofia i Lletres i cursar-hi els estudis de Filologia Clàssica.

Després de llicenciar-se, Valero fou ajudant del Dr. Sebastián Cirac Estopañán ( $†$ 1970), que temps enrere havia estat canonge arxiver de Conca i que en aquell moment era catedràtic de Filologia Grega de la Universitat de Barcelona i responsable de la secció de Bizantinística de la delegació del CSIC a Barcelona. Tanmateix, els treballs acadèmics de Valero -l'antiga tesina de llicenciatura i la tesi doctoral- foren dirigits pel Dr. Josep Alsina, també catedràtic de Filologia Grega de la Universitat de Barcelona. La primera, titulada Los héroes homéricos en Eurípides, fou presentada després d'acabar la llicenciatura l'any 1964; l'any 1970, també sota la direcció acadèmica del Dr. Alsina, Valero defensava la tesi doctoral, presentada amb el títol de El insulto y la invectiva en la literatura griega.

Valero desplegà tota la seva activitat acadèmica a la Universitat de Barcelona, on fou professor encarregat de curs i professor adjunt numerari, adscrit a la primera càtedra de Grec -ocupada aleshores per Sebastián Cirac i successivament per Carlos García Gual- fins esdevenir professor titular de Filologia Grega. Des del mateix moment de la seva creació i durant dotze anys fou Secretari de la nova Facultat de Filologia (1973-1985). S'implicà en la coordinació de les proves d'accés a la Universitat (1976-1988), especialment en la modalitat de majors de 25 anys (des de 1988 i fins a la seva jubilació) i també fou director del Servei d'Esports (1982-1986); de fet, se'l podia trobar sovint a les instal-lacions esportives de la Universitat, al capdamunt de la Diagonal, desplegant la seva inefable bonhomia, quan era saludat per qualsevol membre de la comunitat universitària, independentment de la seva condició laboral i de la seva pertinença disciplinar. Fou també secretari de la Secció Catalana de la Sociedad Española de Estudios Clásicos (1971-1975) i es comptà entre els primers membres de la Societat Catalana d'Estudis Clàssics.

Durant força temps Valero es feu càrrec especialment de les assignatures de "Textos Grecs" en el descurat horari de nocturn que comprenien una vasta gamma d'autors de la Grecitat clàssica (Homer, Hesíode, els poetes lírics, Lísias, Plató, els tràgics), però l'afable professor passava també innombrables estones pels racons de la Facultat, departint jocosament amb tothom disposat a escoltar-lo i explicant mil-i-una anècdotes que, amb amenitat instructiva, cercaven la ironia didàctica. 
Valero s'havia anat interessant, per iniciativa del Dr. Cirac, en la poesia heroica bizantina que acabà essent el seu camp d'especialització. Realitzà diverses estades al Institut für Byzantinistik de Munic, la llar de la bizantinística catalana, i participà en diverses edicions de la principal reunió científica d'aquesta disciplina, els congressos internacionals d'Estudis Bizantins (XIVè congrés, Bucarest 1971; XVIè congrés, Viena 1981).

Certament, el nom de Valero estarà lligat a les dues traduccions d'èpica bizantina que publicà en els primers anys vuitanta a la col-lecció de textos bilingües "Erasmo" de la casa editorial Bosch: el Poema de Digenís Akritas i la Història de Belisari. ${ }^{1}$ Es tracta de poemes no excessivament extensos escrits en vers decapentasil-làbic, representatius de la poesia heroica d'època tardobizantina. Per al primer, Valero va partir d'una de les tres recensiones de l'obra, precisament la conservada en un manuscrit de l'abadia de Grottaferrata -l'actual Biblioteca Statale del Monumento Nazionale di Grottaferrata, ms. Z.a.XLIV (444) (G)-2 que però no n'és la més antiga. En efecte, aquesta última cal identificar-la ${ }^{3}$ amb la conservada al manuscrit de l'Escorial -San Lorenzo de El Escorial, Biblioteca del Real Monasterio, ms. Gr. 496 (olim Y.IV.22) (E)-, descobert per K. Krumbacher, que es presenta com una primera reelaboració erudita, del segle XII, feta a partir del nucli original de l'obra, certament més antic. Partint de l'edició sinòptica d'Erich Trapp, ${ }^{4}$ Valero trasllada al castellà la recensio de G, datada en els segles XII-XIII, que és també el resultat d'una reelaboració que pretén adaptar l'obra als nous gustos i interessos d'un públic culte i cortesà durant el període de la dinastia Paleòloga. Les aventures de Basili Digenís Akritis, el famós defensor de les fronteres d'Anatòlia contra els invasors àrabs (el sobrenom prové del mot grec ăko $\alpha$ "frontera"), situades en un passat heroic, eren precedides d'un llarg estudi introductori sobre la poesia heroica bizantina i les seves característiques com a gènere literari amb un excrursus sobre denominació aplicada al gènere (poesia època, poesia heroica, novel-la èpica).

En el congrés d'Estudis Bizantins de Bucarest, celebrat el 1971, Valero degué tenir notícia de la Història de Belisari, ja que el professor d'Amsterdam i màxim especialista en l'obra, Arnold F. van Gemert, que acabaria fent-ne l'edició crítica de referència, ${ }^{5}$ hi presentà una comunicació sobre un nou manuscrit que contenia el text. ${ }^{6}$ En qualsevol cas, l'any 1983 apareixia la segona traducció de Valero, la Historia y poema de Belisario. L'obra inclou el breu (580 versos) poema anònim sobre Flavi Belisari, amb la descripció fantasiosa de les gestes del gran general, tot sovint fruit de la imaginació de l'autor, com ara la històricament inexistent expedició a Britània. Tanmateix, la traducció va acompanyada d'una extensa introducció històricoliterària -més d'un centenar de

\footnotetext{
${ }^{1}$ El lector podrà trobar una nova versió castellana dels dos poemes a MARTÍNEZ GARCÍA (2003).

2 D'aquest manuscrit havia estat feta una edició crítica amb traducció (Mavrogordato 1956) que Valero coneix. Per a traduccions fetes a partir de la recensió de Grottaferrata, vegeu ODORICO (1995); JOUANNO (1998). Darrerament, hi ha tendència a editar o traduir al mateix temps les dues versions, E i G. Vegeu, per exemple, JEFFREYs (1998). Per a l'obra, vegeu BEATON, RICKS (1993), BEATON (1996).

${ }^{3}$ Alexiou (1985).

4 TRAPP (1971).

${ }^{5}$ Bakker, van Gemert (1988).

${ }^{6}$ VAN GEMERT (1976).
} 
pàgines amb bibliografia final- centrada en la figura del gran comandant justinaneu, amb una profunditat inusual en aquest tipus de traduccions dites "escolars". Com a epíleg, el volum inclou també una àmplia selecció de passatges de l'obra històrica de Procopi de Cesarea, traduïts per Valero, i una selecció de mapes, trets de la traducció italiana de Marcello Cravieri, publicada per Einaudi a la seva coneguda col-lecció "I Millenni". ${ }^{7}$

És precisament entre les línies d'aquesta introducció on reviu encara ara el Valero que tots hem conegut, aquell professor sorneguer que feia servir un castellà genuí, florit i virolat, inusual en els nostres carrers. En el capítol titulat "El desastre matrimonial" Valero es complau a detallar sucosament les desavinences conjugals entre Belisari i Antonina, la seva ambiciosa i emprenedora esposa, en part prenent com a font la Història Secreta de Procopi de Cesarea. La comparació d'Antonina amb Teodora, l'emperadriu i dona de Justinià, és inevitable fins al punt que el traductor les defineix com a "gatas de un mismo tejado"; ; igualment, quan Antonina i Teodora volen maridar dos joves reticents al matrimoni, Valero detalla com l'emperadriu "agarró a los dos asustadizos adolescentes, los encerró en una lujosa estancia y allí los mantuvo durante ocho meses cual a dos retozones animalejos, hasta que se aparearon";" però, probablement, l'escena més picant, protagonitzada per la mateixa Antonina, es produeix poc després quan, en paraules de Valero, Teodosi, l'amant de l'adúltera, en ser descobert in flagranti, "con el cinturón desabrochado y el pantalón caído, dejaba al descubierto tanto la embarazosa situación como, si se me permite, los cuernos del marido". ${ }^{10}$ En reviure en la paraula escrita del nostre professor de grec la seva florida expressivitat lèxica i la causticitat mordaç, tots hi reconeixem aquell to mofaire i burleta amb què Valero ens arrencava sense massa esforços un somriure còmplice. ${ }^{11}$

\section{BIBLIOGRAFIA}

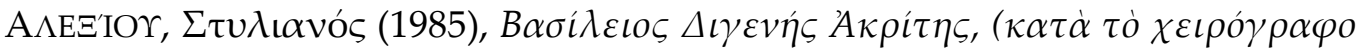

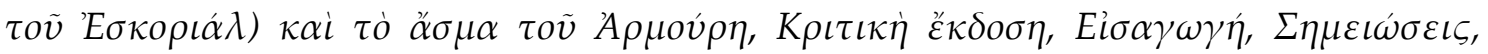

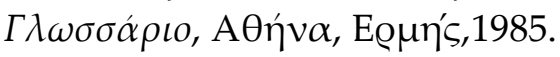

BAKKER, Willem, F., VAN GEMERT, Arnold, F. (1988), I $\sigma \tau o \rho i \alpha ~ \tau o v ~ B \varepsilon \lambda \iota \sigma \alpha \rho i ́ o v$.

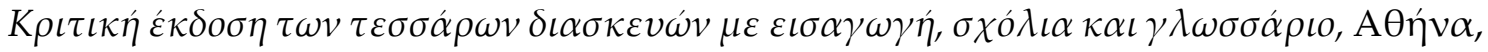

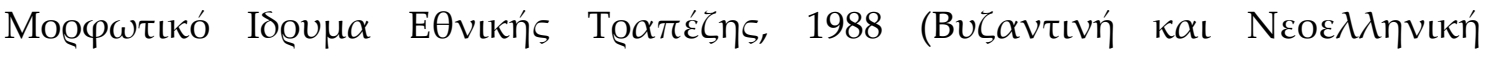

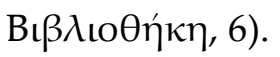

BEATON, Roderich, RICKS, David (1993), Digenes Akrites: New Approaches to Byzantine Heroic Poetry, Aldershot, King's College London, 1993.

BEATON, Roderich (1996), The Medieval Greek Romance, Cambridge, Cambridge University Press, 1996.

CRAVIERI, M. (1977): Procopio de Cesarea. Le Guerre persiana uandalica gotica, a cura di M. Cravieri. Introduzione di F.M. Pontani, Torino, Einaudi, 1977.

\footnotetext{
${ }^{7}$ CRAVIERI (1977).

8 VALERO (1983), p. 101.

${ }^{9}$ VALERO (1983), p. 105.

${ }^{10}$ VALERO (1983), p. 102.

${ }^{11}$ En la mateixa línia, vegeu el sentit record de GRAU (2019).
} 
GRAU, Sergi (2019): "Juan Valero. La pregona humanitat d'un humanista", Auriga. Revista de divulgació $i$ de debat del món clàssic 98, 2019, pp. 20-22.

JEFFREYS, Elizabeth (1998), Digenis Akritis: the Grottaferrata and Escorial Versions, Cambridge, Cambridge University Press, 1998.

JouAnNo, Corinne (1998): Digénis Akritas : le héros des frontières : une épopée byzantine : version de Grottaferrata. Introduction et traduction par Corinne Jouanno, Turnhout, Brepols, 1998.

MARCOS HIERRO, Ernest (2007): Els estudis de bizantí a Catalunya, Ithaca. Quaderns Catalans de Cultura Clàssica 23, 2007, pp. 109-127.

Martínez García, Óscar (2003), Poesía Heroica Bizantina. Canción de Armuris. Digenís Akritas. Poema de Belisario. Traducción directa del griego, Madrid, Editorial Gredos, 2003.

Odorico, Paolo (1985); Digenis Akritas. Poema anonimo bizantino a cura di Paolo Odorico ; prefazione di Enrico V. Maltese, Firenze, Giunti, 1995.

TRAPP, E. (1971): Digenes Akrites. Synoptische Ausgabeder der ältesten Versionen, Wien, H. Böhlaus, 1971 (Wiener Byzantinistische Studien, 8).

VALERO GARRIDO, Juan (1964), Los héroes homéricos en Eurípides, Barcelona, Universitat de Barcelona 1964 [Tesis de licenciatura dirigida por José Alsina Clota].

VALERO GARRIDO, Juan (1970), El insulto y la invectiva en la literatura griega, Barcelona, Universitat de Barcelona, 1970 [Tesis para obtener el grado de doctor; director: José Alsina].

VALERO GARRIDO, Juan (1981), Basilio Digenís Akritas. Introducción, cronología, bibliografía, notas y traducción inédita de Juan Valero Garrido, Barcelona, Ed. Bosch, 1981 (Col. Erasmo Textos Bilingües).

VALERO GARRIDO, Juan (1983), Poema e historia de Belisario. Introducción, traducción y notas de Juan Valero Garrido, Barcelona, Ed. Bosch, 1983 (Col. Erasmo Textos Bilingües).

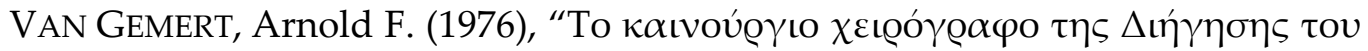

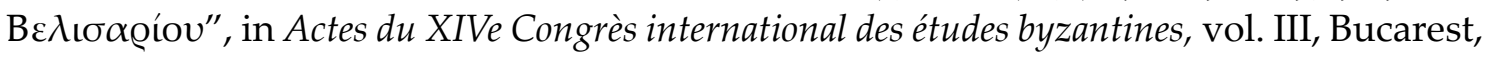
Editura Academiei Republicii Socialiste România, 1976, pp. 77-81. 